\title{
Decomposition and detoxification of DXNs adsorbed on various solid wastes by microwave plasma treatment
}

\author{
R. Sasai ${ }^{1}$, M. Jin-no ${ }^{2}$, A. Satoh ${ }^{2}$, Y. Imai ${ }^{2} \&$ H. Itoh ${ }^{1,2}$ \\ ${ }^{I}$ Division of Environmental Research, EcoTopia Science Institute, \\ Nagoya University, Japan \\ ${ }^{2}$ Department of Applied Chemistry, Graduate School of Engineering, \\ Nagoya University, Japan
}

\begin{abstract}
Microwave plasma treatment of the various solid wastes adsorbed with DXNs was investigated to develop an effective and novel method for in situ detoxification of DXNs in solid wastes such as incinerator fly ashes of the municipal wastes (IFA) or used activated carbons (AC). It was found that the microwave plasma treatment could completely decompose the adsorbed DXNs into inorganic gases such as $\mathrm{Cl}_{2}, \mathrm{CO}_{2}$ and $\mathrm{CH}_{4}$ with low plasma power $(250 \mathrm{~W})$ and short treatment time $(<15 \mathrm{~min})$. Moreover, this decomposition behaviour did not depend on the kinds of solid wastes adsorbed with DXNs. In the case of IFA, the treatment time needed was slightly affected by the amount and/or chemical species of inorganic salt $\left(\mathrm{CuO}, \mathrm{CuCl}_{2}, \mathrm{Ca}(\mathrm{OH})_{2}, \mathrm{CaCl}_{2}\right.$, etc.) contained in the IFA at low plasma power region $(<100 \mathrm{~W})$, but this change was negligible at higher plasma power $(>250 \mathrm{~W})$. The $\mathrm{AC}$ obtained after the microwave plasma treatment exhibited almost the same characteristics of specific surface area, pore size distribution, and pore volume. Furthermore, the weight loss of $\mathrm{AC}$ due to burning and/or ablation could be scarcely observed. This shows that the microwave plasma can selectively decompose the organic species adsorbed on solid matter. Thus, the present microwave plasma treatment was found very useful not only as a decomposition method of the toxic organic compounds on solid, but also as a recycling method of the used inorganic solid adsorbents.
\end{abstract}

Keywords: microwave plasma treatment, DXNs, incinerator fly ash, used activated carbon, detoxification, recycling. 


\section{Introduction}

Dioxin chemicals (DXNs) are generic name of the polychlorinated dibenzo- $p$ dioxin (PCDD), polychlorinated dibenxofurane (PCDF) and coplanar polychlorinated biphenyl (co-PCB). They are typically toxic and hazardous compounds, the discharged amounts of which are strictly controlled all over the world. Today, it is well known that most of the DXNs are emitted from the incinerator of the municipal wastes in Japan and they exist in the exhaust gas produced during incineration. The exhaust gas is detoxified by the electric ash precipitator or adsorbent such as activated carbon (AC), and then released to the atmosphere. These fly ash or adsorbent is discharged as the incineration wastes containing DXNs. Therefore, a proper treatment should be carried out to detoxify these condensed wastes. Usually, these hazardous wastes have been landfilled in the final disposal site after detoxification and/or stabilization treatment such as incineration at very high temperature or solidification into cement. However, these methods give rise to other serious problems like highenergy consumption, high maintenance fee, high $\mathrm{CO}_{2}$ emission, etc. Then, several detoxification technologies have been developed and practically applied in a few cases. The thermal dechlorination and vitrification methods are well known as the detoxification process of DXNs containing IFAs [1-3]. In the former process, the detoxification of DXNs occurs by the substitution of chlorine with hydrogen at $350-550^{\circ} \mathrm{C}$ under poor oxygen atmosphere, but DXNs are resynthesized by de novo reaction during the cooling step [4]. Furthermore, DXNs cannot be detoxified completely even by heating, because the dechlorination occurs only on the surface of fly ash. In the latter process, DXNs are decomposed almost completely during the melting process of IFA at higher temperatures of $1200-1600^{\circ} \mathrm{C}$ in the vitrification process. Resynthesis of DXNs does not occur during this treatment, although a large-scale furnace with a considerably high-energy consumption and cost for the maintenance of the facility must be required.

Activated carbon is frequently used as adsorbent for removing the DXNs from the polluted exhaust gas, which is emitted after removal of the suspended particulate matter by the electric ash precipitator. Today, the used activated carbon with DXNs is not recycled, because there is no effective recycling process of the activated carbon adsorbed with such toxic stable organic molecules. Most of the current recycling methods proposed for the used activated carbon possess some serious problems such as the performance degradation, high energy consumption and low recovery rate.

To solve the above mentioned problems, it is essential to develop a novel process for complete and selective decomposition of DXNs adsorbed on IFA and $\mathrm{AC}$ at lower temperature and with higher efficiency. Here, we adopted a nonequilibrium microwave plasma process with a high reactivity at relatively low ambient temperature. Recently, the microwave plasma process has been applied to decomposition and detoxification of various hazardous gases, such as chlorofluorocarbon, $\mathrm{NO}_{\mathrm{x}}, \mathrm{CO}_{2}$, volatile organic compounds and DXNs. However, there is no application of the microwave plasma treatment to the 
decomposition and detoxification of hazardous organic compounds adsorbed on solid matter. In this study, we attempted both detoxification of IFA adsorbed with DXNs and recovery of AC adsorbed with DXNs by the microwave plasma irradiation.

Table 1: $\quad$ Element composition of IFAs.

\begin{tabular}{rccrccccr}
\hline & $\mathrm{K}$ & $\mathrm{Al}$ & \multicolumn{1}{c}{$\mathrm{Mg}$} & $\mathrm{Cu}$ & $\mathrm{Pb}$ & $\mathrm{Fe}$ & $\mathrm{Ca}$ & $\mathrm{Cd}$ \\
\hline $\mathrm{A}$ & 65.6 & 57.6 & 12.2 & 0.31 & 0.60 & 8.28 & 445 & 0 \\
$\mathrm{~B}$ & 44.8 & 26.0 & 5.6 & 0.74 & 3.99 & 7.75 & 325 & 0 \\
$\mathrm{C}$ & 34.8 & 48.7 & 13.6 & 0.34 & 0.60 & 4.13 & 253 & 0 \\
\hline
\end{tabular}

*Unit is $\mathrm{mg} / \mathrm{g}$.

\section{Experimental}

\subsection{Materials}

Three IFAs received from different emission sources, were used as IFA samples (an average element composition of these IFAs is shown in Table 1). The amount of DXNs contained in these IFAs was (A) 0.17, (B) 1.56, and (C) 3.21 TEQ-ng/g, respectively. Granular activated carbon for adsorbing DXNs (DXN4, Ajinomoto Fine-Techno. Co. Inc.) was used. In the microwave plasma treatment for activated carbon, two kinds of non-toxic polychrolinated dibenzo$p$-dioxin (PCDD: Scheme 1) were used as a model DXN molecule.

(a)<smiles>Clc1cc2c(cc1Cl)Oc1c(Cl)c(Cl)cc(Cl)c1O2</smiles>

(b)<smiles>Clc1cc(Cl)c2c(c1Cl)Oc1c(Cl)c(Cl)c(Cl)c(Cl)c1O2</smiles>

Scheme 1: Chemical structure of PCDD ((a) 5CDD and (b) 7CDD).

\subsection{Preparation of activated carbon with DD}

Granular activated carbon with ca. 200 ng-PCDD/g-AC (AC/PCDD) was prepared by adding AC to $20 \mathrm{~cm}^{3}$ of PCDD diethylether solution, and then evaporating diethylether at room temperature. This as-prepared AC/PCDD was dried at $110^{\circ} \mathrm{C}$ for $3 \mathrm{~h}$ in vacuo.

\subsection{Microwave plasma decomposition treatment}

Figure 1 shows the experimental apparatus for the microwave plasma treatment of solid matter adsorbing DXNs. This apparatus consists of the following four 
parts: (1) decomposition and detoxification quartz reactor, (2) microwave plasma generator and (3) trap for the exhaust gas. A quartz crucible with a cap, in which the sample was charged, was held on a pedestal in a quartz reactor. A constant flow rate $(70 \mathrm{sccm})$ of nitrogen/oxygen mixed gas was streamed at a controlled pressure (15 Torr) during the treatment. The generation of microwave plasma was carried out by the activation of the mixed gas at the microwave power with the frequency of $2.45 \mathrm{GHz}$ from the magnetron of microwave generator. The contaminants in an exhaust gas generated during the treatment were collected in a series of taps for gas, water and organic solvent.

The IFAs with DXNs (1.5 g) were treated at 100 and $150 \mathrm{~W}$ of the microwave power for less than 30 min under $\mathrm{N}_{2}$ atmosphere. The AC/PCDD (1.5 g) were treated at $250 \mathrm{~W}$ of the microwave power for less than 5 and 15 min under the nitrogen/oxygen mixed gas (oxygen content: $\mathrm{O}_{2} /\left(\mathrm{N}_{2}+\mathrm{O}_{2}\right)=0$ or 0.2 ).

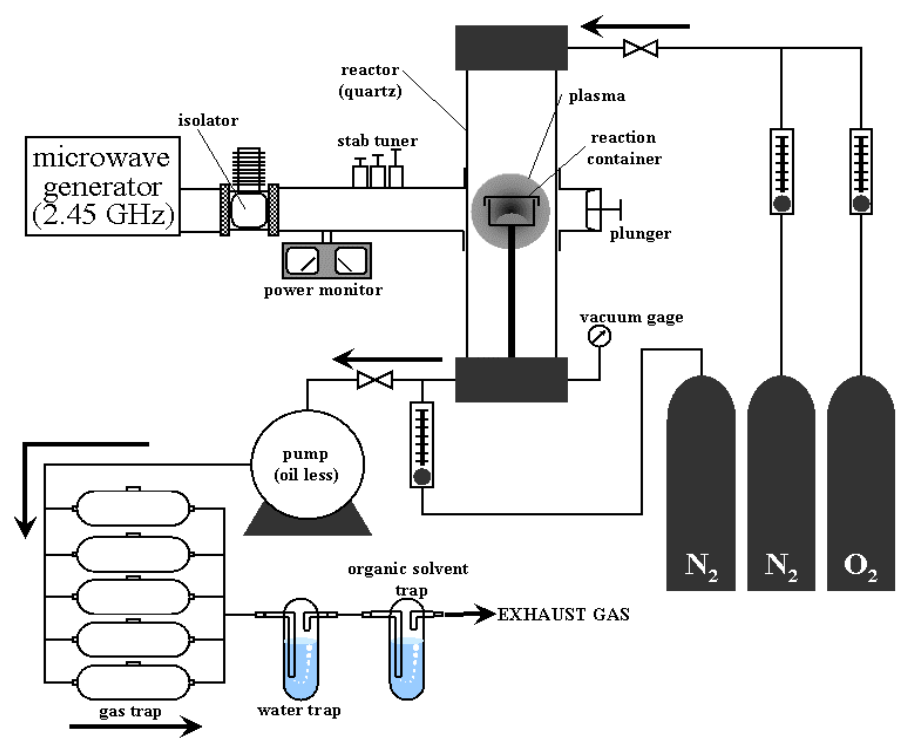

Figure 1: Schematic illustration of the apparatus for the microwave plasma treatment of the solid matter adsorbing DXNs.

\subsection{Characterization}

\subsubsection{IFAs with DXNs}

Crystalline phase variation of the IFAs before and after the microwave plasma treatment at various conditions was examined by the X-ray diffraction (XRD) analysis (Rigaku: RINT-2000). Residual concentration and homologue distribution of DXNs in the IFAs before and after the microwave plasma treatment were evaluated by the gas chromatography-mass spectroscopy (GC- 
MS, JEOL: JMS-700D) analysis of the DXN solution, which was concentrated and extracted by the prescribed method.

\subsubsection{AC with DD}

Residual concentration of PCDD in the AC before and after microwave plasma treatment was estimated from the high resolution GC-MS (JEOL: JMS-700D) spectra of the extracted fractions prepared by the legally assigned technique in Japan. Organic species in the exhaust gas or those dissolved in the liquid trap (in water and toluene) were identified by the GC-MS. Inorganic species in the exhaust gas were analyzed by the GC-TCD (Shimadzu: GC-8A) using the column (Shimadzu GLC: SHINCARBON ST). Inorganic ionic species were measured by the ion-chromatography (Shimadzu: LC-10ADsp) with the electric conductivity detector (Shimadzu: CDD-10Avp) and the anionic exchangeable column (Shimadzu: Simpack IC-A3/IC-GA3).

Characterization of AC before and after the microwave plasma treatment was carried out by the measurement of the specific surface area, pore size distribution and pore volume using nitrogen adsorption technique.

\section{Results and discussion}

\subsection{Microwave plasma treatment of IFAs with DXNs}

Figure 2 shows the treatment time dependence of the removal rate of DXNs (a) and TEQ decrease of IFAs (b), which were obtained after the microwave plasma treatment at $100 \mathrm{~W}$. Total amount and TEQ value of DXNs contained in IFAs decreased exponentially with an increase in the treatment time, and then, the microwave plasma treatment for 30 min could remove most of DXNs from IFAs regardless of the kind of IFA. However, the difference of the removal rate of DXNs among IFAs was observed, when the microwave plasma treatment was carried out for $5 \mathrm{~min}$. Especially, in IFA-(B), the removal rate did not change, and the TEQ value increased by the microwave plasma treatment for $5 \mathrm{~min}$. These results indicate that the amount of DXN species with high toxicity will increase due to the microwave plasma treatment. To clarify the reason of this behaviour, the distribution of DXNs in IFA-(B) treated for 5 min was measured. Table 2 shows that the concentrations of hepta- and octa-chloro-DD (7CDD and $8 \mathrm{CDD}$ ) decreased by the microwave plasma treatment, but those of the hexa-, penta-, and tetra-chloro-DD (6CDD, 5CDD and 4CDD) increased. This means that the dechlorination of DXNs occurs by the microwave plasma treatment under these conditions, but no decomposition of the skeleton structure of DXNs. However, the increasing amount of 4CDD, 5CDD and 6CDD was not the same as that of 7CDD and $8 \mathrm{CDD}$. The de novo synthesis and the chloride addition reaction will be considered as for the production mechanism of 4CDD, 5CDD and 6CDD. Generally, it is known that the highly chlorinated DXN species forms by de novo synthesis. As highly chlorinated DXN species did not increase in the present case, the increase of the lower chlorinated DXN species will be caused by the chlorine removal reaction. This means that the reaction occurs 
preferentially towards lower chlorinated DXN species. Generally, the reason for the dechlorination and chlorination is a catalytic reaction of the inorganic compounds containing $\mathrm{Cu}, \mathrm{Ca}$, etc. during the incineration of municipal wastes. Thus, it is considered that such inorganic species contained in IFA will affect the dechlorination and chlorination reaction of DXNs in IFAs. Moreover, the inorganic compound composition on IFA surface will be important, because the dechlorination and chlorination reaction will occur on the surface of IFA particles. The element composition on the surface of IFAs is shown in Table 3. The amount of $\mathrm{Cu}$ and $\mathrm{Ca}$ on surface of IFA-(B) is found smaller than those of IFA-(A) and -(C). Moreover, the analysis of the main compounds of $\mathrm{Cu}$ and $\mathrm{Ca}$ in IFAs exhibited the presence of hydroxide and chloride. Although the percentage of $\mathrm{Cu}$ compounds did not vary by IFA species, the percentage of $\mathrm{Ca}$ compounds in IFA-(B) was higher than those in IFA-(A) and $-(C)$. This means that the IFA-(B) contains large amount of chloride that would be a chlorine source for DXNs. Therefore, the excess increase of 4CDD, 5CDD and 6CDD in IFA-(B) observed after the microwave plasma treatment for 5 min may be caused by the chloride species of Ca existing on the surface of IFA-(B) particle. On the other hand, it is well known that $\mathrm{Cu}$ species play a role of catalyst for decomposition or dechlorination of DXNs during incineration. The amount of $\mathrm{Cu}$ on surface of IFA-(B) was smaller than that of other IFAs. This fact verifies that the efficiency of the decomposition or dechlorination reaction is the lowest in these IFAs. Thus, it is considered that the remarkable difference observed after the microwave plasma treatment of IFAs for $5 \mathrm{~min}$ can be related to the amount of $\mathrm{Ca}$ and $\mathrm{Cu}$ species on the surface of IFA particle.

Table 2: Distribution of DXNs in IFA-(B) after the microwave plasma at the treatment for $5 \mathrm{~min}$.

\begin{tabular}{crr}
\hline & \multicolumn{2}{c}{$[\mathrm{DXN}](\mathrm{pmol} / \mathrm{g})$} \\
\cline { 2 - 3 } & untreated & treated \\
\hline 4CDD & 41 & 49 \\
5CDD & 41 & 45 \\
6CDD & 45 & 51 \\
7CDD & 57 & 53 \\
8CDD & 70 & 61 \\
\hline
\end{tabular}

Table 3: $\quad$ Element composition on the surface of IFAs.

\begin{tabular}{ccccccccr}
\hline & $\mathrm{K}$ & $\mathrm{Al}$ & $\mathrm{Mg}$ & $\mathrm{Cu}$ & $\mathrm{Pb}$ & $\mathrm{Fe}$ & $\mathrm{Ca}$ & $\mathrm{Cd}$ \\
\hline $\mathrm{A}$ & 7.8 & 3.2 & 1.8 & 3.0 & 1.1 & 0.6 & 32.0 & 0 \\
$\mathrm{~B}$ & 5.4 & 1.6 & 0.8 & 1.8 & 1.7 & 0.4 & 25.4 & 0 \\
$\mathrm{C}$ & 5.7 & 5.0 & 2.3 & 3.7 & 1.1 & 0.6 & 37.7 & 0 \\
\hline
\end{tabular}

* Unit is atomic percentage.

When the microwave plasma power increased up to $150 \mathrm{~W}$, the remarkable difference among three IFAs after the microwave plasma treatment was not 
observed (cf. Figure 3). This would be caused by higher decomposition rate due to the plasma active species with higher energy. These results indicate that the treatment of IFA with DXNs at higher microwave power efficiently decomposes DXNs contained in IFAs to non-toxic inorganic gases such as $\mathrm{CO}_{2}$ and $\mathrm{CH}_{4}$ regardless of the chemical composition of IFAs. It is concluded, therefore, that the microwave plasma treatment is very effective method for complete decomposition of DXNs contained in IFAs, besides this treatment does not select the kinds of IFA species.

\subsection{Microwave plasma treatment of activated carbon with DXNs}

In Table 4, the concentration of DXNs in $\mathrm{AC}$ added 1, 2, 4, 7, 8pentachlorodibenzo- $p$-dioxin (5CDD) or 1, 2, 3, 4, 6, 7, 9-heptachlorodibenzo- $p$ dioxin (7CDD) before and after the microwave plasma treatment at $250 \mathrm{~W}$ is shown. Here, the 4CDD and 6CDD observed before the treatment will be impurity of the 5CDD and 7CDD, respectively. The DXNs concentration in both $\mathrm{AC}$ rapidly decreased with an increase in the treatment time. In the case of AC with 5CDD, no 6CDD, 7CDD and 8CDD species were observed after the microwave plasma treatment for 5 or $15 \mathrm{~min}$. This means that the addition reaction of chlorine to skeleton structure of 5CDD does not occur, and thus, only the dechlorination and/or decomposition of 5CDD skeleton structure occur. On the other hand, the production of 4CDD and 5CDD species was observed after the microwave plasma treatment of the AC with 7CDD. This result indicates that the dechlorination reaction of 7CDD occurs dominantly during the present treatment. Besides, the decomposition reaction of skeleton structure of DXNs occurs because the total amount of DXNs adsorbed on AC is also decreasing. These results lead to the conclusion that the microwave plasma treatment is very effective to remove and decompose the DXN species adsorbed on AC, just as the fly ash with DXNs.

Table 4: Concentration of DXNs in $\mathrm{AC}$ before and after the microwave plasma treatment at $250 \mathrm{~W}$.

\begin{tabular}{rrrr|rrr}
\hline & \multicolumn{5}{c}{ added DXN species } \\
\cline { 2 - 7 } & \multicolumn{7}{c}{ 5CDD } & & \multicolumn{3}{c}{ 7CDD } \\
\hline 4CDD & 7050 & 134 & 30 & 0 & 50 & 0 \\
5CDD & 306914 & 238 & 73 & 0 & 70 & 10 \\
6CDD & 0 & 0 & 0 & 18752 & 109 & 58 \\
7CDD & 0 & 0 & 0 & 253984 & 205 & 106 \\
8CDD & 0 & 0 & 0 & 0 & 0 & 0 \\
\hline
\end{tabular}

unit is $\mathrm{pg} / \mathrm{g}$

In the recovery case of polluted $\mathrm{AC}$, not only the removal and decomposition of DXNs, but also the maintenance of $\mathrm{AC}$ characteristics such as adsorption ability and porosity is very important. In Table 5, the specific surface area of AC 
before and after the microwave plasma treatment at $250 \mathrm{~W}$ is shown. The surface area of AC with DXNs after the microwave plasma treatment was almost the same as that of the virgin AC. Moreover, the pore size distribution and volume of $\mathrm{AC}$ after the treatment were also the same as those of the virgin AC. This shows that the microwave plasma treatment does not seriously affect the properties of AC. Therefore, the present microwave plasma treatment is very effective to recover the AC polluted by DXNs.

Table 5: $\quad$ Specific surface area of AC before and after treatment at $250 \mathrm{~W}$.

\begin{tabular}{|c|c|c|c|c|}
\hline \multirow{3}{*}{$\begin{array}{l}\text { virgin } \\
\text { (before) }\end{array}$} & \multicolumn{4}{|c|}{ after } \\
\hline & \multicolumn{2}{|c|}{$5 \mathrm{CDD}$} & \multicolumn{2}{|c|}{ 7CDD } \\
\hline & $5 \mathrm{~min}$ & $15 \mathrm{~min}$ & $5 \mathrm{~min}$ & $15 \mathrm{~min}$ \\
\hline 1125 & 1126 & 1208 & 1043 & 1171 \\
\hline
\end{tabular}

\section{Conclusions}

The present microwave plasma treatment is one of the powerful techniques for the detoxification of the incineration fly ash and activated carbon polluted with DXNs. In our data, the DXNs including or adsorbing IFAs and AC particles were perfectly decomposed by the microwave plasma treatment with very low energy consumption (i.e., $<250 \mathrm{~W}$ within $15 \mathrm{~min}$ ). In addition, the present microwave plasma treatment brought about no degradation of the adsorption ability and pore structure of AC. Therefore, the microwave plasma treatment is effective to recover the waste $\mathrm{AC}$, which is used for cleaning up the exhaust gas after the incineration. Further development of a large-scale treatment apparatus must be required as a future work for the practical application of our work, because our apparatus can treat only small amount of the solid matter with DXNs $(<$ ca. $10 \mathrm{~g})$.

\section{Acknowledgement}

We thank Mr. K. Ooba, Nagoya City Environmental Science Research Institute, for analyses of the concentrations and the homologue distribution of DXNs, and useful suggestions and discussion on the decomposition of DXNs.

\section{References}

[1] Miyata, H., Dioxin, Iwanami-shinsho: Tokyo, 1999.

[2] Kaneko, H., Hibai-taisaku, NTS: Tokyo, 1998.

[3] Kojima, K., Okajima, S., Ozaki, H., Proc. 13th Annual Conference of The Japan Society of Waste Management Experts, p. 702, 2002.

[4] Wang, Y-F., Lee, W-J., Chen, C-Y., Hsieh, L-T., Environ. Sci. Technol., 33, p. 2234, 1999. 